TESE

\section{Atividade Elétrica Cerebral de Base e Gravidade das Epilepsias}

\author{
Delrio Façanha da Silva*
}

Um estudo prospectivo clínico e eletrencefalográfico foi realizado em 147 pacientes adultos, com epilepsia parcial e generalizada.

O objetivo foi o estudo da atividade elétrica cerebral de base (AECB) em relação à gravidade das epilepsias.

Os pacientes foram classificados segundo a gravidade das epilepsias em três grupos: epilepsias leves, moderadas e graves. Os aspectos clínicos estudados foram a idade de início das epilepsias, a etiologia e o antecedente de status epilepticus. No EEG consideramos: a AECB normal e alentecida, com e sem descargas paroxísticas; as descargas paroxísticas uni e polifocais; a frequêencia das descargas paroxísticas; o foco temporal anterior e o padrão ponta-onda $>3 \mathrm{~Hz} \mathrm{e}<3 \mathrm{~Hz}$.

Este estudo da influência da AECB na gravidade das epilepsias permitiu as seguintes conclusōes:

- a AECB alentecida correlacionou-se com as epilepsias graves;

- a AECB normal correlacionou-se com as epilepsias não graves;

- a idade precoce de início das epilepsias não se correlacionou com a gravidade das epilepsias;

- o antecedente de status epilepticus não se correlacionou com a gravidade das epilepsias;

- o foco temporal anterior isoladamente, unifocal ou polifocal, não se correlacionou com a gravidade das epilepsias;

- o número de focos no EEG, a freqüência das descargas paroxísticas, o EEG com descarga paroxística focal ou generalizada não influenciaram a gravidade das epilepsias.

- os pacientes com o padrão ponta-onda $>3 \mathrm{~Hz}$ ou $<$ $3 \mathrm{~Hz}$, correlacionaram-se com as epilepsias graves, quando na presença da AECB alentecida;

- a etiologia conhecida correlacionou-se com as epilepsias graves, quando associadas a AECB alentecida.

\section{ARTIGOS}

\section{The Motor Disorder of Multiple System Atrophy}

\author{
Quinn, N.P. \& Marsden, C.D. \\ J. Neurol. Neurosurg. Psychiatry 1993; 56:1239-42 \\ Paulo, H. F. Bertolucci*
}

O termo atrofia multi-sistêmica (AMS), a partir de sua introdução por Graham e Oppenheimer, em trabalho descrevendo um paciente com insuficiência autonômica, ataxia cerebelar e sinais piramidais, teve sua aplicação ampliada para outras doenças cerebrais degenerativas. Contudo a AMS é específica, e apenas uma das degenerações multisistêmicas. Para caracterizá-la, é possível usar duas metodologias: estudo prospectivo, com diagnóstico in vivo, sujeito a um grau de incerteza; estudo retrospectivo de casos patologicamente confirmados. Este trabalho apresenta resultados em 188 indivíduos com AMS demonstrada por exame anatomo-patológico, isto é, casos de início na idade adulta, esporádicos, com atrofia estriatonigral ou olivopontocerebelar, ou ambas.

Sinais de parkinsonismo foram notados em $89 \%$, geralmente em associação com sinais piramidais ou cerebelares, ou ambos. Apesar disso, um em cada 4 pacientes deste grupo apresentava exclusivamente parkinsonismo, indicando que o diagnóstico diferencial entre AMS e doença de Parkinson pode ser um problema não infreqüente. Embora assimetria no início da doença e o tremor característico não sejam comuns na AMS, existem exceçōes. Mais útil é lembrar a característica falta de resposta à L-Dopa nesta moléstia.

Os sinais cerebelares, mais raramente, são o quadro inicial da AMS. Por outro lado, estes sinais estavam presentes em pouco mais da metade dos pacientes, em geral associados a sinais piramidais. O mais comum é a ataxia. Foram também observados tremor postural e disartria, progredindo a anartria nos estágios finais da doença.

Sinais piramidais foram vistos em $62 \%$ dos pacientes, com exceção de um único paciente, associados a alterações cerebelares e parkinsonismo, sozinhos ou em combinação. O mais comum foi hiperreflexia e resposta plantar em extensão. Algumas vezes observou-se espasticidade, de diagnóstico mais difícil, na presença da rigidez plástica associada.

Alteraçōes autonômicas precederam as motoras e estavam presentes em $77 \%$ dos pacientes com parkinsonismo e $86 \%$ daqueles sem estes sintomas. $\mathrm{O}$ mais comumente observado foi hipotensão postural, impotência e incontinência urinária.

Em resumo, o principal diagnóstico diferencial foi com doença de Parkinson. Pode ser útil a verificação da ataxia, incontinência urinária e a já referida ausência de resposta à L-Dopa, que falam a favor de AMS.

Tese de doutorado - Neurologia - Escola Paulista de Medicina.

- Professor Adjunto, Doutor - Disciplina de Neurologia da Escola Paulista de Medicina. 


\section{ARTIGOS}

\section{Permanent Global Amnesia with Unknown Etiology}

\author{
Kritchevsky $M$; Squire $L R$ \\ Neurology 1993; 43:326-32 \\ Paulo H. F. Bertolucci*
}

A perda de memória severa, permanente e isolada está associada com dano bilateral ao lobo temporal medial ou a estruturas diencefálicas mediais. Pode haver várias causas para a amnesia: cirurgia para epilepsia, anoxia, envenenamento por monóxido de carbono, encefalite viral, encefalite paraneoplásica, síndrome de Korsakoff, traumatismo de crânio, etc. Em todas estas situações existe algum dado de história ou exame que permite o diagnóstico.

Este artigo descreve três pacientes que desenvolveram amnesia severa e relativamente isolada sem causa identificável.

O primeiro paciente, um engenheiro de 63 anos, desenvolveu severa dificuldade de memória ao longo de 3 dias. Um ano antes ele havia sido encontrado inconsciente, convulsionando, como conseqüência de um infarto miocárdico. Além disso, apresentava hipertensão leve. O exame neurológico mostrou exclusivamente alteração de memória (inclusive para a data do exame). A RNM mostrou atrofia de hipocampos, com lobos temporais e giros para-hipo-campais normais. O seguimento por 6 anos não mostrou alteração no déficit cognitivo.

O segundo paciente desenvolveu déficit de memória ao longo de 2 anos, a partir dos 69 anos de idade. Havia história de alcoolismo, que havia cessado quando os sintomas começaram. $O$ pai e um tio paterno tinham doença de Alzheimer. O exame neurológico, à parte a dificuldade de memória e para desenhar um relógio, foi normal. A RNM mostrou redução bilateral dos hipocampos e discreta redução dos lobos temporais.

O terceiro paciente, com 65 anos, desenvolveu severa dificuldade de memória ao longo de 2 anos. O exame neurológico foi normal, exceto por severo déficit de memória de fixação e retrograda. A RNM mostrou marcada redução no volume dos hipocampos. Havia redução também dos giros para-hipocampais e
corpos mamilares.

Dois dos pacientes não apresentaram declínio cognitivo 6 e 7 anos após o início do déficit de memória. $O$ segundo parece ter declínio 8 anos após o início da amnesia.

Estes pacientes não parecem enquadrar-se em qualquer das etiologias de amnesia citadas acima. A doença de Alzheimer pode apresentar-se como déficit isolado de memória, mas nẫo existe caso bem documentado em que esta situação tenha persistido por mais de 3 anos. É possível que estes pacientes tenham desenvolvido amnesia como consequeência de episódios rápidos e repetidos de hipotensão relativa. O primeiro paciente apresentou pelo menos um episódio no qual pode ter havido arritmia cardíaca, mas para os outros dois esta possibilidade é menos evidente.

Professor Adjunto, Doutor - Disciplina de Neurologia da Escola Paulista de Medicina.

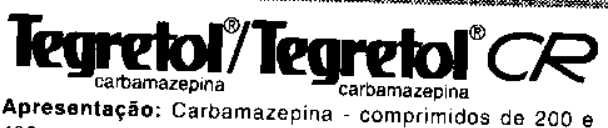
400mg: comprimidos CR (liberação controlada divisiveis) de 200 e $400 \mathrm{mg}$; xarope $100 \mathrm{mg} / 5 \mathrm{ml}$. Indlcaçöes: Epilepsia (crises parciais, crises generalizadas primárias ou secundárias com componente tònico-clônico, mistas). Usualmente nāo e efetiva em ausências (pequeno mal). Mania e tratamento profilatico de distúrbios maniaco-depressivos (bipolares). Sindrome de abstinência alcoólica. Neuralgia do trigèmio, neuralgia idiopatica do glossofaringeo. Neuropatia diabética dolorosa. Diabetes insipidus centralis. Dosagem: iniciar o tratamento com doses baixas (por exemplo: aduttos - Epilepsia: $100-200 \mathrm{mg}$, uma ou duas vezes ao dia. Neuralgia do trigèmเo: $200-400 \mathrm{mg} / \mathrm{dia}$; surto de mania: 200-600mg/dia), as quais devem ser gradualmente aumentadas até 800-1.600mg/dia, dependendo da indicaçao e gravidade da doença. crianças - $10-20 \mathrm{mg} / \mathrm{kg} /$ dia Admınistraçāo em doses divididas. Vide intormaçỏes completas para pre scriçào. Contra-indicaçōes: Hipersensibilıdade conhecida a carbamazepina ou a drogas estruturalmente relacionadas. Bloqueio atrioventricular. História de depressāo de medula ossea ou portiria intermitente aguda. Uso concomitante de inibidores da MAO. Advertências: Anemia aplastica, agranulocilose: hematometria completa e monitorizacáo do, agranureaçōes graves de pele. Vide informaçòes completas para pres. criçảo. Precauçōes: Gravidez e lactaçào. História de disturbios cardiaco. renal ou hepático ou reaçóes adversas hematologicas a outras drogas; sinais e sintomas precoces de reacóes potencialmente hematológicas, dermatológicas ou hepatıcas. Dirigir veiculos ou operar máquinas. Testes de funçào hepatica periodicos e urinálise. Pressão intra-ocular: ativaçào de psicose latente, confusāo, agitaçâo; pacientes idosos. Crises mistas. inciuindo ausências atipicas; interrupção abrupta do tratamento. Monitorização dos niveis plasmáticos. Outras drogas antiepilepticas; benzodiazepinicos, haloperidol, tioridazina, corticosteróides, contraceptivos orais, ciclosporina, digoxina, doxiciclina. eritromicina, trioleandomicina, possivelmente josamicina. isoniazida, diltiazem, felodipina, verapamis, imipramina, metadona, dextropoxifeno, anticoagulantes orais, viloxazina. possivelmente cimetidina, danazol, possivelmente nicotinamida: lítio, metoclopramida, teofilina acetazolamida, hidrociorotiazida, furosemida, miorrelaxantes nāo despolarizantes (ex.: pancuronium), isotretinoina, álcool. Vide informaçỏes completas para prescrição. Reaçöes adversas: Sistema Nervoso Centrai . Ocasional e normalmente no inicio do tratamento, sendo tran. sitórias: vertigens e diplopia; raramente: ataxia e movimentos involuntários; casos isolados: neurites periféricas, alucınaçỏes. depressảo, agitaçāo, comportamento agressivo. Pele - bran das: frequentes: reaçōes ałergicas dérmicas: raramente reaçóes dermicas graves. por exemplo: dermatites esfoliatıvas sindrome de Stevens-Johnson; casos isolados: Sindrome de Lyel, queda de cabelos. Sangue - brandas; freqũentes: leucopena: ocasionalmente: trombocitopenia; casos isolados: agranulocitose. anemia aplastica. Figado - ocasionalmente: elevaçáo das enzımas plasmatıcas: raramente: ictericia e hepatite Gastromtestinal - Ocasionalmente: vómitos; raramente: diarréia: casos isolados: dor abdominal. Reaçōes de hipersensibilidade. Hipersensibilıdade tarđia de varios órgàos com febre. erupçōes culâneas, vasculıtes. leucocitoses, eosinofilia, tinfoadenopatia, artralgia, hepaloesplenomegalia: raramente podem ser afetados oulros órgaos como, por exemplo: pulmōes, rins, pàncreas, mıcardıo: casos ısolados: reaçào anafilatica: raramente: sindrome "Lupus-like". Sistema cardiovascular - Raramente: arritmias: casos isolados: bradicardia. bioqueio atrioventricular, Insuficiencia cardiaca congestiva $\theta$ tromboembolia, distúrbios da pressáo sangüinea e agravamento de doenças arteriocoronarias. Sistema endocrno - Ocasionalmente : retençāo de liquido. ganho de peso, hiponatremia; isoladamente: ginecomastia ou galactorrèa, tesles anormais da funçäo tireoideana, distúrbios do metabolismo osseo, osteomalacia. Urogenital - Casos isolados: disfunçâo renal, nefrite intersticial, disturbios sexuais. Diversos - Ocasionalmente: distúrbios de acomodaçăo visual; casos isolados: distúrbios do paladar, opacidade do cristalino, conjuntivite, zumbido, dor muscular. Vide informaçöes comple. tas para prescriça. Embalagens: TEGRETOL": comprimidos de 200 ou $400 \mathrm{mg}$; carxas com 20 unidades; xarope $100 \mathrm{mg} / 5 \mathrm{ml}$; vidros com $100 \mathrm{ml}$. TEGRETOL CR DIVITABS: comprimidos divisiveis de liberaçảo controlada: 200 ou $400 \mathrm{mg}$; caixas com 20 unidades. Informaçöes completas para prescriçào a dis posiçào da classe médıca mediante solicitaçào.
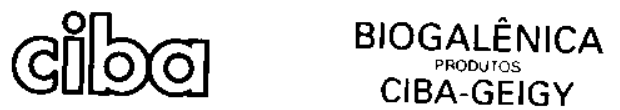

Hot-line (Tel.) 0800-113003 - Horảı comercial (ligaçao gratuita) BIOGALÉNICA - Av. Prot Vicente Rao. 90/120- Portāo B Prédio 156 - CEP 04706-900 - Sào Paulo - SP 